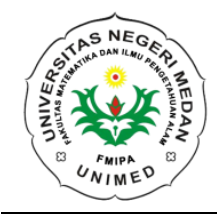

\author{
JURNAL EINSTEIN \\ Jurnal Hasil Penelitian Bindang Fisika \\ Available online http://jurnal.unimed.ac.id/2012/index.php/einsten \\ e-issn: $2407-747 x$, p-issn $2338-1981$
}

\title{
ANALISIS SIFAT MEKANIK KOMPON KARET
}

\author{
Elfariska Sidebang dan Nurdin Bukit \\ Jurusan Fisika, Fakultas Matematika dan Ilmu Pengetahuan Alam, Universitas Negeri Medan, \\ Indonesia \\ Elfariska96@gmail.com
}

Diterima April 2018; Disetujui Mei 2018; Dipublikasikan Juni 2018

\begin{abstract}
ABSTRAK
Penelitian ini bertujuan untuk mengetahui nilai sifat mekanik kompon karet. Pengujian karakteristik kompon karet yaitu kekerasan, kekuatan tarik, dan perpanjangan putus, dengan menggunakan variasi bahan pengisi Nanopartikel abu boiler kelapa sawit $(0 \%, 2 \%, 4 \%, 6 \%, 8 \%)$ berat. Alat pengujian yang digunakan dalam penelitian ini yaitu Durometer untuk pengujian kekerasan dan Tensiometer untuk pengujian Kekuatan tarik dan perpanjangan putus. Metode yang digunakan dalam pembuatan nanopartikel abu boiler kelapa sawit yaitu dengan menggunakan metode kopresipatasi dengan ukuran 56,31 nm. Dari hasila nalisis diperoleh sifat mekanis pada kekerasan, kekuatan tarik dan perpanjangan putus mengalami peningkatan dengan bertambahnya variasi bahan pengisi abu boiler kelapa sawit.
\end{abstract}

Kata Kunci : Kompon Karet, Abu Boiler Kelapa Sawit.

\section{PENDAHULUAN}

Nanoteknologi adalah ilmu dan rekayasa dalam penciptaan material, struktur fungsional, maupun piranti dalam skala nanometer. Partikel koloid atau disperse partikel yang berukuran antara 1-100 nm (sub-mikron) dikenal dengan nanopartikelPenelitian di bidang nanopartikel menghasilkan sifat material yang unik, yaitu material berskala nano memiliki sifat yang lebih unggul dari material yang berukuran besar (bulk). Dalam menciptakan material baru yang berkualitas tinggi diperlukan penggabungan atau pengkombinasian dari dua atau lebih unsurunsur dasar yang berbeda satu diantaranya berfungsi sebagai matriks dan lainnya berfungsi sebagai filler atau pengisi/penguat.

Abu boiler kelapa sawit (ABKS) dapat dimanfaatkan sebagai filler memberikan keuntungan secara ekonomis dan ramah lingkungan. Abu boiler kelapa sawit adalah abu yang telah mengalami proses penggilingan pada proses pembakaran cangkang dan serat bua nh pada suhu $500-700^{\circ} \mathrm{C}$ pada dapur tungku boiler. Abu kelapa sawit dari sisa pembakaran cangkang dan serabut buah kelapa sawit mengandung unsur silica $\left(\mathrm{SiO}_{2}\right)$ sebanyak $31,45 \%$ dan unsur kapur (CaO) sebanyak 15,2\%. Pembakaran cangkang dan serat buah menghasilkan kerak yang keras berwarna putih keabuan akibat pembakaran dengan suhu tinggi dengan kandungan silica 49,2\% (Awal et al,2010).

Telah banyak penelitian yang membuat tentang campuran abu boiler kelapa sawit (ABKS) dengan karet alam antara lain: campuran abu boiler kelapa sawit dengan karet alam SIR-20 (Tambunan,N,M,2017), campuran abu boiler kelapa sawit dengan HDPE (ginting,E,M,dkk.,2015), campuran nanopartikel abu boiler kelapa sawit dengan LDPE (Noer,2017), ABKS/kompon karet SIR20/polypropylene (Bahruddin,dkk.,2007). Berdasarkan penelitian yang dilakukan ternyata 
limbah abu kelapa sawit banyak mengandung unsur silica $\left(\mathrm{SiO}_{2}\right)$ yang merupakan bahan pozzolanic (Ermiyati,2007).

Pembuatan nanopartikel dapat dilakukan dengan beberapa metode seperti: reaksi sol-gel, sonochemical, kopresipitasi (Fernandez, 2011). Diantara metode ini peneliti memilih menggunakan metode kopresipitasi, karena lebih murah dan sederhana. Metode ini mudah dilakukan, dapat dilakukan secara kontinyu, selain itu bahan dan cara kerja lebih sederhana. Proses kopresipitasi berlangsung pada suhu rendah $\left(70^{\circ} \mathrm{C}\right)$, mudah mengontrol ukuran partikel, sehingga waktu yang dibutuhkan relatif singkat. Metode kopresipirasi merupakan metode yang digunakan untuk mensintesis serbuk polimer dengan penambahan HCL sebagai pelarut dan $\mathrm{NH}_{4} \mathrm{OH}$ sebagai pengendapn ya dengan harapan akan menghasilkan nanopartikel(Sholinah,2010).

Pembuatan nanopartikel abu boiler kelapa sawit dilakukan dengan menggunakan ballmill dan metode kopresipitasi. Abu boiler kelapa sawit di ballmill PM 200 selama 1 jam, diayak menggunakan ayakanberukuran 200 mesh $(74 \mu \mathrm{m})$. Selanjutnya dengan metode kopresipitasidimana dilarutkan dengan $\mathrm{HCl} 2 \mathrm{M}$ dan $\mathrm{NaOH} 3 \mathrm{M}$ untuk mendapatkan Nanopartikel.dilakukan pengkarakterisasian dengan XRD dan XRF, untuk mengetahui ukuran dan unsur yang terkandung dalam abu boiler kelapa sawit. Hasil analisis XRD dari nanopartikel abu boiler kelapa sawit diperoleh ukuran kristal 56,31 nm.

Kompon karet adalah merupakan turunan yang paling utama dari komoditi karet. Hampir semua kompon karet menggunakan carbon black sebagai bahan pengisi (filler). Bahan pengisi carbon black berfungsi sebagai penguat (reinforcing), memperbesar volume, memperbaiki sifat-sifat fisik dari barang-barang karet dan memperkuat vulkanisat. Dari Kompon karet yang dihasilkan dapat dipalikasikan atau dimanfaatkan dalam pembuatan sol sepatu, sarung tangan, dan ban kenderaan bermotor.

Telah banyak penelitian yang melakukan tentang pembuatan kompon karet (Nasution,2017),(Ali,dkk.,2014),(Nuyah,2013), membuat variasi perbandingan yang berbeda dalam pembuatan kompon karet tersebut. Dalam penelitian ini, peniliti akan membuat kompon karet dengan perbandingan karet alam/ABKS (phr) yaitu 100/0, 98/2, 96/4, 94/6, 92/8 dan begitu juga dengan perbandingan antara karet dengan carbon black.

\section{METODE PENLITIAN}

Penelitian ini akan dilakukan di Laboratorium Fisika Fakultas Matematika dan Ilmu Pengetahuan Alam Universitas Negeri Medan danPusatPenelitianKaret Bogor.

\section{Alat dan Bahan}

Alat yang digunakan yaitu Tensiometer, Durometer,Rheometer dan bahan yaitu Wax, Asam streat, ZnO, Sulfur, IPPD, TMTD,MBTS

\section{Pembuatan nanopartikel ABKS dengan metode kopresipitasi}

1. Abu boiler kelapa sawit dikeringkan menggunkan furnance selama 1 jam dengan suhu $150^{\circ} \mathrm{C}$

2. Abu boiler yang sudah kering di haluskan menggunakan ball mill selama 1 jam pada kecepatan $250 \mathrm{rpm}$. Kemudian diayak menggunakan ayakan 200 mesh.

3. Langkah selanjutnya melakukan metode kopresipitasi yaitu dengan cara pengendapan. Abu boiler kelapa sawit yang telah disaring di timbang dengan massa 10 gr di larutkan dalam HCL 2M sebanyak $40 \mathrm{ml}$, diaduk dengan magnetic stirrer dengan suhu $70^{\circ} \mathrm{C}$ selama 40 menit dan setelah pengadukan selesai dilakukan penyaringan dengan menggunakan kertas saring.

4. Setelah disaring abu boiler kelapa sawit yang mengendap di kertas saring dimasukkan kembali ke dalam beaker glass, kemudian di campur dengan $\mathrm{NaOH}$ $3 \mathrm{M}$ sebanyak $40 \mathrm{ml}$, kemudian diaduk selama 40 menit dengan suhu $70^{\circ} \mathrm{C}$ menggunakan magnetic stirrer.

5. Setelah proses pengadukan selesai, dilakukan penyaringan kembali menggunakan kertas saring.

6. Setelah disaring, abu boiler kelapa sawit yang mengendap pada kertas saring dimasukkan kedalam beaker glass yang lebih besar dan di cuci menggunakan 
aquades. Tunggu hingga abu boiler kelapa sawit mengendap kedasar beaker glass, kemudian aquades tersebut dibuang dan di ulangi sebanyak tiga kali.

7. abu boiler yang mengendap dikeringkan menggunakan oven selama 4 jam dengan suhu $\quad 70^{\circ} \mathrm{C}$ Dan dikarakterisasi menggunkan XRD.

\section{Pembuatan Kompon Karet}

1. Menimbang bahan-bahan kompon karet yaitu karet SIR-20, zinc oxide( $\mathrm{ZnO})$, asam stearate, ABKS, carbon black, Wax, IPPD, TMTD, MBTS neraca digital dengan memvariasikan filler ABKS dab filler Carbon black.

2. Setelah bahan-bahan ditimbang, karet SIR-20 dimasukkan kedalam mesin roll mill, lalu digiling hingga karet benarbenar padat.

3. Sambil berjalannya proses penggilingan karet, bahan-bahan dimasukkan satupersatu secara bertahap ke dalam rheometer.

Tabel 1.komposisi campuran bahan formula kompon dalam phr dengan filler ABKS dan CB.

\begin{tabular}{|c|c|c|c|c|c|c|c|c|c|c|c|}
\hline \multirow[t]{3}{*}{$\begin{array}{l}\mathrm{N} \\
0\end{array}$} & \multirow[t]{3}{*}{ Bahan-bahan } & \multicolumn{9}{|c|}{$\begin{array}{l}\text { Formula kompon } \\
\text { (perhundred rasio) }\end{array}$} & \multirow[t]{3}{*}{ Fungsi } \\
\hline & & \multirow{2}{*}{$\begin{array}{l}- \\
S_{1}\end{array}$} & \multicolumn{3}{|c|}{ ABKS } & \multicolumn{5}{|c|}{ Carbon black } & \\
\hline & & & $\mathrm{S}_{2}$ & $\mathrm{~S}_{3}$ & $\mathrm{~S}_{4}$ & $\mathrm{~S}_{5}$ & $\mathrm{~S}_{6}$ & $\mathrm{~S}_{7}$ & $\mathrm{~S}_{8}$ & $\mathrm{~S}_{9}$ & \\
\hline 1 & karet SIR-20 & 100 & 98 & 96 & 94 & 92 & 98 & 96 & 94 & 92 & Binder \\
\hline 2 & Wax & 1,5 & 1,5 & 1,5 & 1,5 & 1,5 & 1,5 & 1,5 & 1,5 & 1,5 & Antilux \\
\hline 3 & Filler & 0 & 2 & 4 & 6 & 8 & 2 & 4 & 6 & 8 & Filler \\
\hline 4 & $\mathrm{ZnO}$ & 5 & 5 & 5 & 5 & 5 & 5 & 5 & 5 & 5 & Activator \\
\hline 5 & Asam streat & 2 & 2 & 2 & 2 & 2 & 2 & 2 & 2 & 2 & Activator \\
\hline 6 & Sulfur & 3 & 3 & 3 & 3 & 3 & 3 & 3 & 3 & 3 & $\begin{array}{l}\text { Curing } \\
\text { agent }\end{array}$ \\
\hline 7 & IPPD & 2 & 2 & 2 & 2 & 2 & 2 & 2 & 2 & 2 & Antioksidan \\
\hline 8 & TMTD & 1,5 & 1,5 & 1,5 & 1,5 & 1,5 & 1,5 & 1,5 & 1,5 & 1,5 & Accelerator \\
\hline 9 & MBTS & 2,5 & 2,5 & 2,5 & 2,5 & 2,5 & 2,5 & 2,5 & 2,5 & 2,5 & Accelerator \\
\hline
\end{tabular}

Tabel 2.Komposisi campuran bahan formula Kompon dalam gram

\begin{tabular}{|c|c|c|c|c|c|c|c|c|c|c|}
\hline \multirow[t]{3}{*}{$\begin{array}{l}\mathrm{N} \\
0\end{array}$} & \multirow[t]{3}{*}{ Bahan-bahan } & \multicolumn{9}{|c|}{$\begin{array}{c}\text { Fomula kompon } \\
\text { (gram) }\end{array}$} \\
\hline & & \multirow{2}{*}{$\begin{array}{l}- \\
S_{1}\end{array}$} & \multicolumn{2}{|c|}{ ABKS } & \multicolumn{6}{|c|}{ Carbon black } \\
\hline & & & $\mathrm{S}_{2}$ & $\mathrm{~S}_{3}$ & $\mathrm{~S}_{4}$ & $\mathrm{~S}_{5}$ & $S_{6}$ & $\mathrm{~S}_{7}$ & $\mathrm{~S}_{8}$ & $\mathrm{~S}_{9}$ \\
\hline$\overline{1}$ & karet SIR-20 & 130 & 127,4 & 124,8 & 122,7 & 119,6 & 127,4 & 124,8 & 122,2 & 119,6 \\
\hline 2 & Wax & 1,95 & 1,95 & 1,95 & 1,95 & 1,95 & 1,95 & 1,95 & 1,95 & 1,95 \\
\hline 3 & Filler & 0 & 2,6 & 5,2 & 7,8 & 10,4 & 2,6 & 5,2 & 7,8 & 10,4 \\
\hline 4 & $\mathrm{ZnO}$ & 6,5 & 6,5 & 6,5 & 6,5 & 6,5 & 6,5 & 6,5 & 6,5 & 6,5 \\
\hline 5 & Asam streat & 2,6 & 2,6 & 2,6 & 2,6 & 2,6 & 2,6 & 2,6 & 2,6 & 2,6 \\
\hline 6 & Sulfur & 3,9 & 3,9 & 3,9 & 3,9 & 3,9 & 3,9 & 3,9 & 3,9 & 2,6 \\
\hline 7 & IPPD & 2,6 & 2,6 & 2,6 & 2,6 & 2,6 & 2,6 & 2,6 & 2,6 & 2,6 \\
\hline 8 & TMTD & 1,95 & 1,95 & 1,95 & 1,95 & 1,95 & 1,95 & 1,95 & 1,95 & 1,95 \\
\hline 9 & MBTS & 3,25 & 3,25 & 3,25 & 3,25 & 3,25 & 3,25 & 3,25 & 3,25 & 3,25 \\
\hline
\end{tabular}

\section{HASIL DAN PEMBAHASAN}

Analisis Sintesis Nanopartikel Abu boiler kelapa sawit.

Pengujian XRD ( $X$-Ray Diffraction) dilakukan untuk mendapatkan pola difraksi, struktur kristalin dan ukuran partikel dari nanopartikel OPBA. XRD yang digunakan Shimadzu $6100(40 \mathrm{kV}, 30 \mathrm{~mA})$ dengan panjang gelombang $\mathrm{Cu}-\mathrm{Ka} 1=1.5405 \AA=0.15406$ nm.dengan laju $2 \%$ menit pada rentang sudut $2 \theta=$ $5^{\circ}-70^{\circ}$. Pengujian XRD dilakukan pada suhu ruang dan menggunakan nikel untuk menyaring radiasi CuKa. Ukuran kristalit sampel dihitung berdasarkan analisis metode Scherrer dari pola difraksi sinar X.

Pola difraksi XRD diperoleh ukuran partikel dengan cara menghitung besarnya FWHM (Full Width at Half Maximum) dari puncak difraksi melalui pendekatan persamaan Scherrer. FWHM dikonversi ke dalam satuan radian dengan dikalikan $\pi / 180$.

$$
D=\frac{K \lambda}{\beta \cos \theta}
$$

Dengan $\beta, K, \lambda$ dan $D$ berturut-turut adalah lebar setengah puncak Full Width at Half Maximum (FWHM) dalam radian, konstanta scherrer $(0,9)$, panjang gelombang sinar- $\mathrm{X}$ $(1,5406 \AA)$, dan D adalah diameter kristal (nm).Berdasarkan hasil analisa software Match version 3 puncak pola difraksi tertinggi yaitu pada $2 \theta: 21,9040^{\circ} ; 26,6200^{\circ} ; 25,7000^{\circ}$. Puncak maksimum terdapat pada sudut $2 \theta=$ 26,6200 engan jarak 3,34594 Å. Pada gambar 4.2 menampilkan puncak pola difraksi tertinggi yang merupakan senyawa SiO2. Hasil pola difraksi sinar- $\mathrm{x}$ nanopartikel abu boiler kelapa sawit 
memiliki fasa quartz $\left(\mathrm{SiO}_{2}\right)$ dan kristal trigonal dengan orientasi bidang kristal [ [ $\left.\begin{array}{llll}0 & 1 & 1\end{array}\right],\left[\begin{array}{lll}1 & 0 & 0\end{array}\right]$ dan $\left[\begin{array}{lll}1 & 1 & 2\end{array}\right]$ serta parameter kisi $\mathrm{a}=4,9130 \AA$ dan $\mathrm{c}=$ $5,4050 \AA$ dan memiliki massa 2.649000 $\mathrm{g} / \mathrm{cm}^{3}$.Dengan perhitungan dari persamaan 1 diperoleh rata-rata ukuran partikel untuk variasi larutan $\mathrm{NaOH} 3 \mathrm{M}$ di peroleh ukuran kristal sebesar 56,31 nm. Hasil analisis intensitas puncak ditunjukkan pada Gambar 1.

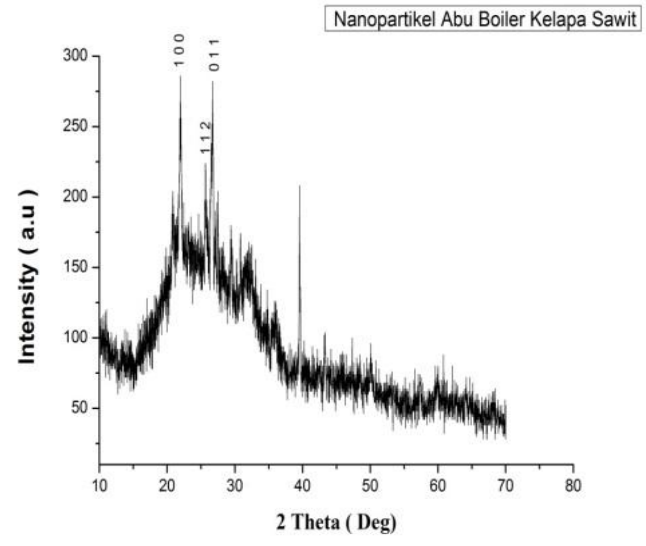

Gambar 1. Pola difraksi XRD nanopartikel abu boiler kelapa sawit.

Analisis Sifat Mekanik Kompon Karet dengan menggunakan filler ABKS dan carbon black

\section{Kekerasan}

Berdasarkan karakterisasi yang dilakukan dengan mesin uji mekanis diperoleh data kekerasan seperti diperlihatkan pada Tabel berikut.

Tabel 3. Hasil pengujian kekerasan Kompon Karet.

\begin{tabular}{cc}
\hline $\begin{array}{c}\text { Komposisi filler } \\
(\%)\end{array}$ & $\begin{array}{c}\text { Kekerasan (Shore A) } \\
(\text { ABKS) }\end{array}$ \\
\hline Tanpa filler & 50 \\
2 & 50 \\
4 & 50 \\
6 & 50 \\
8 & 52 \\
\hline
\end{tabular}

Uji Kekerasan (Hardness) dilakukan untuk mengetahui besarnya kekerasan vulkanist karet, dilakukan dengan kekuatan tertentu dengan menggunakan alat Durometer Shore. Hasil pengujian Hubungan kekerasan terhadap komposisi ABKS dapat dilihat pada gambar 2.

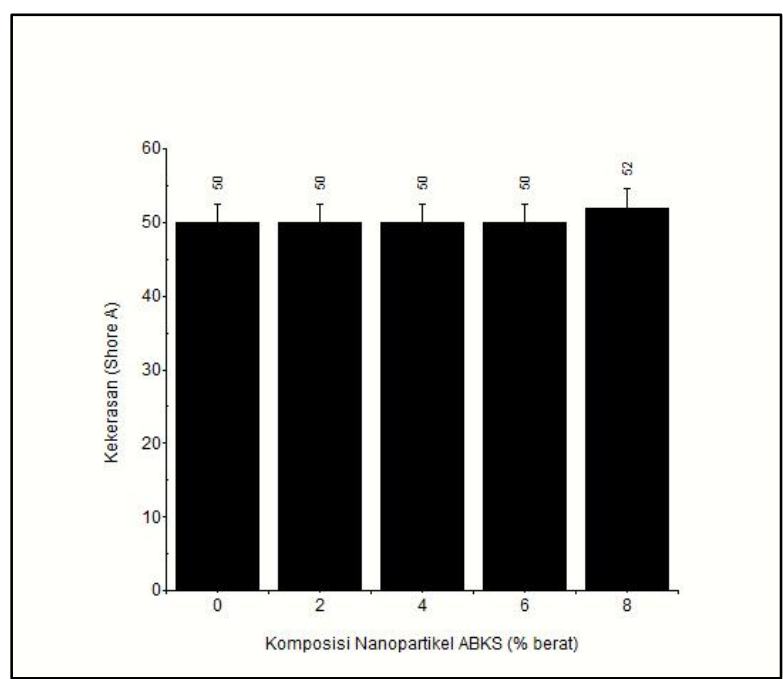

Gambar 2. Hubungan Kekerasan terhadap Komposisi Nanopartikel ABKS

Nilai kekerasan kompon karet dengan bahan pengisi Nnaopartikel ABKS mengalami peningkatan dibandingkan dengan nilai kekerasan kompon karet tanpa bahan pengisi. Peningkatan nilai kekerasan kompon karet adalah disebabkan karena kandungan silika pada ABKS yang lebih cenderung meningkatkan kekerasan (hardness). Semakin besar komposisi $\mathrm{SiO}_{2}$ didalam matriks, maka sifat yang dihasilkan semakin keras.

Nilai kekerasan terbesar adalah pada filler ABKS $8 \%$ yaitu 52 Shore A. Hal ini menunjukkan nilai kekerasan yang lebih baik dari penelitian (Hildayati,2009) dimana dalam penelitian ini digunakan silika powder sebagai penguat matriks karet alam yaitu 36,67 Shore A. Dengan nilai kekerasan yang diperoleh pada pada gambar 2 dapat digunakan untuk proses pembuatan kompon ban dalam kendaraan bermotor $50 \pm 5$ (Shore A).

\section{2. kekuatan tarik}

Berdasarkan karakterisasi yang dilakukan dengan mesin uji mekanis diperoleh data kekuatan tarik seperti diperlihatkan pada Tabel berikut.

Tabel 4. Hasil pengujian kekuatantarik Kompon Karet.

\begin{tabular}{cc}
\hline $\begin{array}{c}\text { Komposisi filler } \\
(\%)\end{array}$ & $\begin{array}{c}\text { Kekuatan tarik } \\
(\mathrm{MPa}) \\
(\mathrm{ABKS})\end{array}$ \\
\hline Tanpa filler & 1,0 \\
2 & 1,3 \\
\hline
\end{tabular}




\begin{tabular}{ll}
\hline 4 & 1,5 \\
6 & 1,5 \\
8 & 1,7 \\
\hline
\end{tabular}

Hasil pengujian Hubungan kekutan tarik terhadap komposisi ABKS dapat dilihat pada gambar 3 .

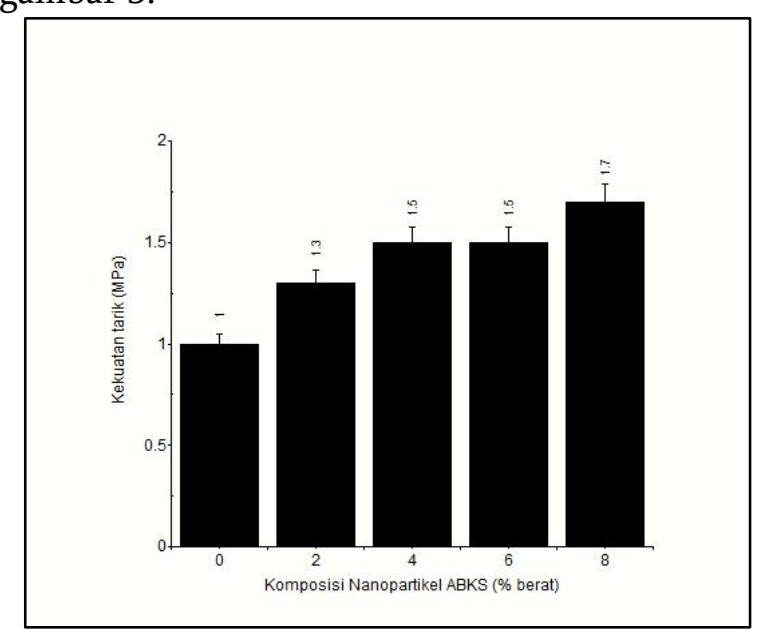

Gambar 3. Hubungan Kekuatan Tarik terhadap Komposisi ABKS

Nilai kekuatan tarik kompon karet mengalami peningkatan setelah diberikan dengan bahan pengisi Nanopartikel ABKS. Penambahan Nanopartikel ABKS menambah kekuatan tarik karena adanya peningkatan ikatan kovalen dan hidrogen dengan grup $\mathrm{OH}$ dan oksigen dari grup karboksil yang masing- masing menambah ikatan antara pengisi dengan matrik karet alam (Ginting, 2015) Namun pada peneilitian ini, didapatkan nilai kekuatan tarik yang lebih sedikit dibandingkan dengan penelitian (Tambunan,2017).

\section{Perpanjangan putus}

Berdasarkan karakterisasi yang dilakukan dengan mesin uji mekanis diperoleh data perpanjangan putus seperti diperlihatkan pada Tabel berikut.

Tabel 5. Hasil pengujian kekuatantarik Kompon Karet.

\begin{tabular}{cc}
\hline $\begin{array}{c}\text { Komposisi filler } \\
(\%)\end{array}$ & $\begin{array}{c}\text { Kekuatan tarik } \\
(\mathrm{MPa}) \\
(\mathrm{ABKS})\end{array}$ \\
\hline Tanpa filler & 1,0 \\
2 & 1,3 \\
4 & 1,5 \\
6 & 1,5 \\
\hline
\end{tabular}

\begin{tabular}{ll}
\hline 8 & 1,7 \\
\hline
\end{tabular}

Hasil pengujian Hubungan kekutan tarik terhadap komposisi ABKS dapat dilihat pada gambar 4 .

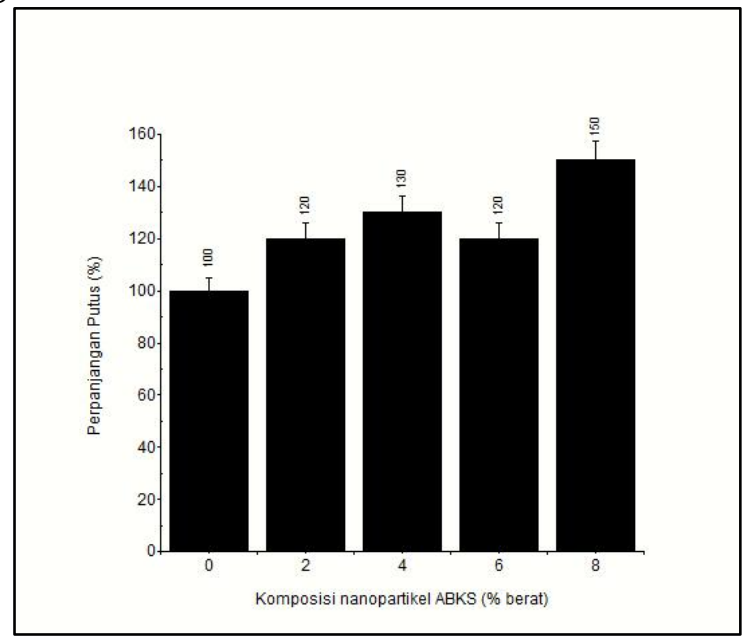

Gambar 4. Hubungan perpanjangan putus terhadap Komposisi ABKS

Nilai perpanjangan putus kompon karet dengan bahan pengisi mengalami peningkatan dibandingkan dengan nilai perpanjangan putus kompon karet tanpa bahan pengisi. Hal ini disebabkan karena kompon karet yang dihasilkan tidak kaku atau tidak keras, Sehingga mudah untuk diregangkan maka memiliki nilai perpanjangan putus yang besar. Namun pada sampel ke empat dengan (ABKS 6\%) mengalami penurunan perpanjangan putus dikarenkan kompon yang dihasilkan sulit untuk diregangkan maka dihasilkan nilai perpanjangan putus yang rendah.

\section{KESIMPULAN DAN SARAN}

1. Hasil karakterisasi XRD nanopartikel abu boiler kelapa sawit yang dilakukan dengan menggunakan ballmill dan metode kopresipitasi menunjukkan ukuran partikel abu boiler kelapa sawit yaitu $56.31 \mathrm{~nm}$.

2. Komposisi terbaik kompon karet dengan bahan pengisi nanopartikel abu boiler kelapa sawit yaitu $8 \%$ berat menunjukkan kekerasansebesar 52 Shore A, Kekuatan Tarik sebesar $1.7 \mathrm{MPa}$, Perpanjangan putus 150\%. Dan komposisi terbaik pada bahan pengisi carbon black $8 \%$ berat juga 
dengankekerasansebesar 55 Shore A, Kekuatan Tarik sebesar 2.5 MPa, Perpanjangan putus $140 \%$. dan dengan nilai kekerasan yang diperoleh dapatdigunakan untuk proses pembuatan kompon ban dalam kendaraan bermotor $50 \pm 5$ (Shore A) (SNI 06-1542-2006) dan nilai perpanjangan putus yang diperoleh dapat digunakan untuk proses pembuatan kompon sol sepatu Min 100 (\%) ( SNI 12-0172-1987) dan pembuatan kompon sol luar sepatu Min 100 (\%) (SNI 12-0172-2 005).

\section{Saran}

Pada penelitian selanjutnya disarankan melakukan pembuatan kompon karet dengan variasi yang lain untuk mendapatkannilai kompon yang lebih tinggi.

\section{DAFTAR PUSTAKA}

Ali, Farida., D, R, Mezal, M., H, Darmawan, Valencia., (2014), pengaruh penambahan zeolite dan kulit kerang darah terhadap sifat mekanis rubber compound, jurnal teknik kimia, 20(3): 57-63

Awal, A, S, M, And Nguong, S, K, (2010) A ShortTerm Investigation On High Volume Palm Oil Fuel Ash (Pofa) Concrete 35th , Conference On Our World In Concrete \& Structures,Singapore.

Bahruddin, Wibawa, G, Sumarno, Soewarno, N., (2007), Morfologi Dan Properti Campuran Karet Alam/Polypropylene Yang Divulkanisasi Dinamik Dalam Internal Mixer,Reaktor, 11(2) : 71-77

Ermiyati., (2007), Abu kelapa sawit sebagai pengganti sebagaian semen terhadap kuat tekan dan resapan air pada mortar, jurnal sains dan teknologi, 2(6): 31-34

Fernandez, B.R., (2011), nanomaterial sisntesis, karaterisasi ,sifat dan peralatan elektronik, pascasarjana unuversitas Andalas, Padang, 1-4.

Ginting, M, E., Bukit, N., Frida, E., (2015), Mechanical properties and Mophology natural rubber blend with bentonit and carbon black, IOP conf.series: Material science and Engineering, 223(2016) 012003.

Hildayati., Triwikantoro., Faisal,H., dan Sudirman., (2009), Sintesis dan karakterisasi bahan komposit karet alam- Silika, seminar Nasional pascasarjana IX-ITS, 12Agustus 2009, Surabaya

Nanda, Novarisa, Hara., Bahruddin., Fadli, Ahmad., (2014), pengaruh Maleated natural rubber terhadap Morfologi dan sifat Thermoset Rubber dengan filler abu sawit-carbon black, JOM FTEKNIK,1(2):1-13

Noer, Z., (2017), Pembuatan Dan Karakterisasi Nanopartikel Abu Boiler Kelapa Sawit Dan Carbon Black Sebagai Bahan Pengisi Nanokomposit Termoplastik LDPE, Program Studi Magister Fisika FMIPA-USU, Medan.

Nuyah., Rahmaniar., (2013) pembuatan kompon karet dengan bahan pengisi arang cangkang sawit, jurnal dinamika penelitian industry, 24(2):114-121

Tambunan, M, N., (2017), Pembuatan Dan Karakterisasi Kompon Karet Dengan Filler Nanopartikel Abu Boiler Kelapa Sawit Dan Carbon Black, program studi Sarjana Fisika FMIPAUNIMED,Medan. 